\title{
Observations on a leptospirosis case with ocular determinations
}

\author{
Lucian Negruțiu \\ From The 9th Edition of the Scientific Days of the National Institute for Infectious Diseases Prof Dr Matei Bals \\ Bucharest, Romania. 23-25 October 2013
}

\section{Background}

Leptospira infection or icterohemorrhagic disease (LIR) are not rare entities. Our study introduces a patient infected with LIR following repeated professional underwater dives.

\section{Case report}

Because of disturbances in visual acuity, the patient initially turned to the services of the Timişoara Ophthalmological Clinic in 2011, and was later sent to the Infectious Diseases Clinic of Timişoara, showing low grade fever, moderate hepatosplenomegaly, discreet subicteric sclera and a severely increasing deterioration of visual acuity.

Direct ophthalmoscopy revealed disseminated bilateral chorioretinitis foci. The Infectious Diseases Clinic Laboratory confirmed hematological and serological diagnosis of LIR.

\section{Conclusion}

The ocular chorioretinal determination of LIR is not frequent. In such situations, inoculation particularities along with evolving clinical and biological characteristics invite the clinician to extend the area of investigation.

Submit your next manuscript to BioMed Central and take full advantage of:

- Convenient online submission

- Thorough peer review

- No space constraints or color figure charges

- Immediate publication on acceptance

- Inclusion in PubMed, CAS, Scopus and Google Scholar

- Research which is freely available for redistribution 